\title{
El pecado original en el Antiguo Testamento
}

Las relaciones de Dios con la humanidad han sido fundamentalmente concebidas por Israel bajo la noción de Alianza. Este es el tema principal de la Teología del A. T. El pecado no es más que el aspecto negativo, la oposición a la relación amical. Es así natural que la Escritura hable frecuentemente de esta triste experiencia, en la que el hombre se enfrenta con Dios. $Y$ aunque lo primero sea la gracia, los autores no se olvidan del pecado, ya que éste en definitiva sirve para apreciar mejor el don de la amistad con Dios.

I. El pecado original originado.

El A. T. ha expresado esta idea con muchos términos, ninguno de los cuales corresponde exactamente con el concepto que de él nosotnos tenemos. Y es que los israelitas no llegaron jamás a presentar una noción elaborada y especulativa del pecado, como se concluye por la extrema variedad de términos, que emplea para calificar esta experiencia humana.

1. Noción y naturaleza del pecado ${ }^{1}$.-Tres términos son los más frecuentes y los que, por tanto, deben atraer nuestra atención: $h t$ ', ' $w n$ y $p$ sh'.

La raíz ht' significa literalmente "errar el blanco", "fallar el tiro". Algunas veces (Jue 20, 16; Job 5, 24; Ps 25, 8; Isa 65, 20) conserva aún

1 No es nuestro objeto el estudio de la noción del pecado en el A. T. Nos limitamos simplemente a exponer algunas características de este concepto. Para una mayor intormación sobre la Hamartiología del A. T., cfr. G. QuELL - G. BERtram - G. Staehilin - W. Grundmann, ThWNT, I, 267-295; R. CRIado, "El concepto de pecado en el A. T.": XVIII Semana Bíblica Española, Madrid 1960, 5-49; A. GEIIN, "Le péché dans l'Ancien Testament": Théologie du péché (Bibliothèque de Théologie, Série II), Tournai 1960, 23-47; S. PorúbCAN, Sin in the Old Testament, Rom 1963; E. Beaucamp - E. de Places - S. Lyonnet, DBS VII, Paris 1966, 407-567; R. KNIERIM, Die Hauptbegriffe für Sünde im A.T., Gütersloh 1965. 
su sentido profano. Principalmente, sin embargo, se usa en sentido religioso, entendiéndose por ella, la falta, mala conducta o negligencia que impide conseguir, alcanzar o conservar lo que la norma de comunidad intenta guardar. Quien peca ( $h t^{\prime}$ ) falla el objetivo al que debía dirigirse. Se comprende fácilmente que este término designe el estado de frustración, producido por el acto malo (Num 32, 23; Isa 58, I; Ez 18, 4-5) ${ }^{2}$.

El término ' $w n$, muy frecuentemente empleado como nombre, relativamente raro como verbo -en lo que debe verse ya una tendencia a designar un estado más que un acto-, significa "doblar", "estar doblado", "desviarse", "extraviarse". "Ordinariamente no indica una acción singular, sino el estado fatal, en que cae el pecador después de la mala acción" ". De aquí que se acerque a lo que nosotros entendemos por culpabilidad o sentimiento de culpabilidad, que grava al pecador como un peso, que puede ser transportado, quitado o expiado (Gen 4, 13; Ex 28, $3^{8}$; Lev 16,22$)$. Este término califica más bien al sujeto y a la iniquidad resultante de los hechos pecaminosos (Ps 32, 5 ; Jer 35, 8).

El tercer término, psh', es la calificación más grave del pecado 4 . Tiene su origen probablemente en el ámbito político y presupone la relación de un pacto, que con el acto malo, se rompe o se interrumpe. Indica así la rebelión contra la palabra dada, hostilidad contra la comunidad de la que se forma parte, y sobre todo contra Dios, que es el partner de la Alianza. Entre los profietas sirve para designar el pecado de Israel contra el Dios de la Alianza: la apostasía, la obstinación del pueblo que Yahvé eligió "para ser su pueblo predilecto de entre todos los pueblos de la tierra" (Deut 7,6 ; cfr. Os 7, $13 ; 8,1$; 14, 10; Miq 1, 5; 3, 8; 7 , $18 ; \operatorname{Jer} 2,8-29 ; 3,13 ; 5,6$, etc.).

"Los tres términos expresan, cada uno a su manera y con matices particulares, la idea de ruptura de la Alianza entre Yahvé y el pueblo" . $P s h^{\prime}$, la rebelión de la voluntad humana contra la voluntad de Dios; ht', la aberración, el extravío, la falta (etimológicamente de fallar); ' $w n$, la iniquidad resultante del acto malo.

En definitiva, estos términos, así como otros que pudiéramos citar, presuponen una norma establecida, de la cual se desvía el pecador. Esta

2 E. BEAUCAMr, a. c., 442.

3 J. SCHARBERT, Prolegomena eines Alttestamentlers zur Erbsündenlehre (Quaestiones disputatae 37), Freiburg 1968, 54.

4 G. von RaD, Theologie des Alten Testaments, I, München 1957, 262.

5 E. BEAUCAMP, a. c., 445 . 
norma estaba formada primitivamente por las castumbres y leyes que regulaban la armonía del clan o de la tribu ${ }^{6}$. El Dios de Israel era garante de este orden comunitario, además parte contractuai, y de ahí que cualquier lesión de las leyes fuera considerada como un verdadero pecado contra Dios. El tema central de la Alianza con Yahvé, en la que quedaron integradas las normas que regulaban el comportamiento del individuo en la comunidad, es la que ha ofrecido la base a los autores bíblicos, para calificar el pecado, ya que éste no es ni más ni menos que la otra cara de la medalla, es decir, de la Alianza. No es extraño así que los diferentes términos empleados para designar el pecado sean términos de relación.

La postura correcta de los miembros de la comunidad ante Dios, no podía ser otra que la obediencia: "escuchar mi voz" (Ex 19, 5 y particularmente característica de la literatura deuteronomista), que en el lenguaje de los sabios recibe el nombre de temor de Dios (Prov 10, 27; $14,26.27 ; 15,16 ; 19,23$, etc.), y que otros autores designan con estas expresiones: "andar en el camino de Yahvé, con Yahvé, ante Yahvé o en la ley de Yahvé (Gen 5, 22-24; 6, 9; 17, I ; 48, 15; Lev 18, 3; 26, 3, etcétera).

Por el contrario, el pecado es "no escuchar la voz de Yahvé" fórmula familiar del Dtr (Deut I, 43; 8, 20; 9, 23; 28, 15.45.62), y de la literatura emparentada con ella (Jer $3,3.25 ; 7,28 ; 9,13 ; 40,3)$. Ya de esta manera, aunque no con las mismas expresiones, Oseas e Isaías habían considerado el pecado como una negativa a aceptar las cláusulas de la Alianza (Isa 5, 24; Os 8, I2). Esto es lo que explica que se haya podido decir con toda razón que para Israel "la desobediencia es el pecado original y la quintaesencia de todos los pecados, grandes o pequeños" ?. En efecto, el J en su relato sobre el primer pecado (Gen 2-3) lo describe como una desobediencia. Esto es lo que se concluye del esquema de alianza que ha adoptado para dar una representación plástica a su reflexión teológica sobre el pecado ${ }^{8}$.

6 Sobre el primitivo carácter comunitario de la ética israelita, cr. J. HEMPEL, Ilas Ethos des $A$. T., Berlin 1964, 2 ed.; E. Hammershaimb, "On the Ethics of the Old Testament Prophets": Supplementum to Vetus Testamentum, Leiden 1960, 75-101; - E. JACOB, "Les Bases théologiques de l'éthique de l'Ancien Testament", ib, 39-51; J. L'Hour, La Morale de l'Alliance, Paris 1966.

7 L. KorhLER, Theologie des A. T., Tübingen 1936, 198.

8 L. AlONSO-SCHOEKEL, "Motivos sapienciales y de Alianza en Gen 2-3": Biblica 43 (1962) 295-316, especialmente 305-309. 
De aquí resulta una importante característica del concepto de pecado que tenían los israelitas. La relación que subyace a la noción de pecado no es la de creatura a Creador, sino la relación personal entre los dos partners de la Alianza. No se es pecador por el mero hecho de ser creatura (esto sería la finitud del hombre), sino porque el hombre se rebela contra Dios y no acepta las cláusulas de la Alianza ${ }^{9}$.

Una segunda característica conviene resaltar: el pecado es además una categoría social. Debido a la mentalidad de clan y de comunidad que domina toda la ética israelítica, el pecado no es un fenómeno que interesa sólo al individuo que lo comete, sino también al grupo humano en que está integrado. En el caso de que la comunidad no se desolidarice del pecador, la Alianza común con Yahvé está rota ${ }^{10}$. El pecado en efecto, desencadena un mal que pronto o tarde irrumpirá sobre el individuo y la comunidad que le acoge, pues el castigo no es algo externo al pecado. He aquí una tercera nota digna de tenerse en cuenta. Nuestra mentalidad moderna separa estrictamente el acto malo de sus consecuencias. El castigo es algo sobreañadido, que viene después del pecado y del exterior. En cambio, según el A. T. el pecado engendra la desgracia (Gen 4, 13; Ez 38, ro; Zac I4, I9). El pecado y el castigo, el mai moral y el mal físico no son más que dos aspectos de la misma realidad ${ }^{11}$.

Esta coherencia entre pecado y sus consecuencias ha suscitado una disputa acerca de la retribución en el A. T. En un famoso estudio, $\mathrm{K}$. Koch ${ }^{12}$ señalaba que, según el A. T., el mal desemboca necesariamente en el castigo. El A. T. presentaría el mal como una acción humana que desencadena automáticamente ei castigo en virtud de una fuerza inmanente, y no en virtud de la intervención de Dios que castiga o premia con una pena o un mérito sobreañadido. El error de K. Koch es haber reducido demasiado la intervención de Yahvé ${ }^{13}$, que por oierto en algunos textos es acentuada (Os 4, 9 ; I3, I2; Isa 66, 4 ; Job 40, I2-14). En todo caso, el pecado es una potencia mortal que amenaza al individuo

\footnotetext{
9 P. Ricoevr, "Culpabilité tragique et culpabilité biblique": Revue d'Histoire et de Philosophie Religieuses 33 (1953) 285-307.

10 J. Scharbert, o. c., 56.

11 G. von RAD, o. c., I, 263; E. BEAuCAMP, a. c., 410-445. Los dos términos $h t$ ' $\mathrm{y}$ ' $w n$ indican el acto malo y sus consecuencias, cfr. Núm. 32, 23; Deut. 24, 16; Ez. 33, 10; Zac. 14, 19; Isa. 1,4; 64, 5. El mal moral y el mal físico son una solla realidad, cfr. Isa. 47, 10-11; Jer. 11, 17; Deut. 31, 29; Prov. 17, 13.

12 K. КосH, "Gibt es ein Vergeltungsproblem im A. T."?: Zeitschrift für Theologie und Kirche 52 (1955) 1-42.

18 Véase la observación de G. von RAD, o. c., I, 264, nota 175.
} 
y a la comunidad y que siempre es considerado con sus consecuencias y la intervención de Yahvé ${ }^{14}$.

2. Universalidad del pecado.—Esta potencia de muerte, el pecado, cuyas características hemos anotado, atañe generalmente a todos los hombres. Ya el J alude a la universalidad del pecado como causa del diluvio $(\mathrm{Gen} 6,5)$. La misma constatación se repite después de este acontecimiento (Gen 8, 2I) manifestándose así claramente cuál es su mentalidad respecto de la pecaminosidad del hombre. A estas afirmaciones hace eco el Código Sacerdotal (Gen 6, 12-13), para quien la corrupción general de toda la carne motiva el castigo impuesto por Dios con el diluvio.

Aunque estos y otros textos que citaremos más adelante pudieran interpretarse quizá de la pecaminosidad del hombre debido a su ser creado, la insistencia con que los profetas acusan a Israel y describen su historia, no deja lugar a dudas de que tienen una noción depurada y estricta del pecado como rebelión y oposición a Dios y de su extensión general. La historia de Israel es una historia de pecado (Ez 23; Isa I, 4 ; Cfr Isa 5, 7). El mismo profeta Isaías es consciente de su impureza y de su solidaridad con un pueblo impuro (Isa 6, 5); impureza que es un verdadero pecado, puesto que el ángel le purifica de su pecado y de su iniquidad (Isa 6, 7). Para Miqueas $(7,2)$ "el hombre piadoso ha desaparecido de la tierra: no hay" ningún justo entre los hombres". A quien hace eco Jeremías $(5, \mathrm{I})$ que se lamenta de no encontrar en Jerusalén un hombre que practique la justicia. La afirmación de I Re 8, 46: "no hay hombre que no peque" es frecuentemente ratificada por los sabios (Eccle 7, 20; Job 9, 2; 25, 4; Prov 20, 9) y los psalmistas (Ps 14, 2-3; 130, 3).

A veces, sin embargo, ciertos autores se glorían de su propia justicia (Ps 26), como Job que se declara inocente (Job 31); a pesar de todo, reconocen el propio pecado, al igual que los profetas que eran conscientes de su impureza (Isa 6, 7; Jer I). Es, por tanto, natural entender la contraposición entre justos y malvados, tan frecuente en los libros sapienciales (en Prov 46 veces) en sentido relativo: son justos comparados con los impíos, aunque no haya que excluir cierto pietismo farisaico de algunos que se glorían de su fidelidad a la ley ${ }^{15}$.

14 J. ScharberT, o. c., 57-58.

16 A. GELIN, o. 0., 41 . 
El pecado no es sólo común a todos los hombres, sino que también parece que atañe al hombre desde el primer momento de su existencia, incluso desde la concepción en el seno materno: "Yo en iniquidad nací y en pecado me concibió mi madre" (Ps 5I, 7). Parece aquí que el pecado fuera congenital al hombre. Semejante proceso de remontar al comienzo de la existencia humana para sorprender el pecado, se advierte en el Ps 58, 4 en el que se dice a los jueces malvados: "Desde el seno se desviaron los impíos, se descanriaron desde el vientre los mentirosos". El mismo proceso se advierte en el II Isaías, que dirigiéndose a Israel, dice: "eres absolutamente infiel y te han llamado desleal desde el vientre de tu madre" (Isa 48, 8). En todos estos lugares se manifiesta el mismo proceso de remontar, bien a la primera existencia de Israel, del impío $o$ del hombre en general ${ }^{16}$, para hacer la afirmación que ya desde entonces estaban sujetos al pecado. Ordinariamente se está de acuerdo en negar que el Ps 5I, 7 ofrezca por sí solo base suficiente para construir la teoría diel pecado, como heredado y transmitido por generación. Para los israelitas, las relaciones sexuales (Lev 15, 19-20), lo mismo que el parto (Lev 12, 2-3) ocasionaban impurezas rituales y posiblemente es a esto a lo que el autor alude y nada permite suponer que haya buscado una causa más profunda ${ }^{17}$. El autor, por otra parte, tiene una conciencia aguda del pecado, que sorprende continuamente en la existencia humana, y nada más natural que recurrir a la concepción y al nacimiento, donde ve el origen del pecado y de la naturaleza humana. En este caso, el texto aludiría a la fragilidad de la naturaleza del hombre, como causa y origen del pecado ${ }^{18}$. Bajo este punto de vista, este versículo está en armonía con un buen número de textos, que afirman que el origen del pecado está en la debilidad humana. Este es el sentido de la observación del J: "las inclinaciones del hombre son malas desde su juventud" (Gen 8, 21 ; cfr 6, 5). La debilidad del hombre es tal que no tiene nada de extraño que peque ${ }^{19}$.

16 Generalmente se excluye que el Ps. 51, 7 aluda a un caso particular, por ejemplo, que el autor haya sido concebido en adulterio. Se acepta que habla del hombre en general.

17 A.-M. DuBarle, Le péché originel dans l'Ecriture, Paris 1967, 2 ed., 21. Sobre este texto véase J. K. ZINK, "Uncleaness and Sin. A Study of Job XIV, 4 and Psalm LI, 7": Vetus Testamentum 17 (1967) 354-361.

$18 \mathrm{~K}$. ConDoN, "The biblical doctrine of original Sin": Irish Theological Quarterly 34 (1967) 26-27.

19 H. HAAG, Biblische Schöpfungslehre und kirchliche Erbsündenlehre (Stuttgarter Bibelstudien 10), Stuttgant 1967, 58, nota 67. 
A la misma explicación recurre el autor del libro de Job (4, 17-19): "¿Puede el hombre ser justo ante Dios: un mortai puede ser puro ante su autor?". Nótese el perfecto paralelismo entre las dos frases. Hay una especie de identificación entre la impureza por ser hombre y su injusticia. El autor da como supuesto que el hombre por ser tal, debido a su fragilidad no puede estar sin pecado ante Dios. Un poco más adelante (Job I4, 4) vuelve sobre la misma idea: "Quién puede sacar lo puro de lo impuro? Nadie". Dada la fragilidad de la naturaleza humana, es inútil esperar que sea pura y justa.

Igualmente los Psalmistas son de la misma opinión. Dios perdona a los hombres "porque El sabe nuestra hechura, se acuerda de que somos polvo" (Ps 103, 13s). De hecho éste es el motivo al que recurren frecuentemente para implorar el perdón de sus culpas (Ps 22; 30; 78, 38-39; $89,48 ; 90,3)$. Finalmente, los sabios en los consejos que prodigan, suponen asimismo la debilidad de la naturaleza humana. Sus severas amonestaciones se dirigen principalmente a que el hombre esté atento a los movimientos de su corazón y se ejercite en el control de sí mismo (Prov I5, 10; 19, 18; 23, 3-14).

Los profetas generalmente profundizan más y sorprenden la raíz del pecado en el corazón del hombre. Particularmente Jeremías, que ha estudiado a fondo la pervensión del hombre, ve en ei corazón, el origen del pecado. "El corazón es más engañoso que cualquier otra cosa y es incurable. ¿Quién lo conoce? (Jer. 17, 9). El endurecimiento, que no es exclusivo de Israel, sino común a todas las naciones (Jer 3,17 ) es la raíz de todos los pecados (Jer 7, 24; 9, I3; I I, 8; 13, I0) y crea una especie de segunda naturaleza, de la que es difícil liberanse: "¿Muda el cusita su piel o el leopardo sus pintas? 'También vosotros podéis entonces hacer el bien, los acostumbrados a hacer el mal!" (Jer 13, 23).

Así pues, el A. T. prepara la doctrina de S. Pablo sobre la universalidad del pecado y ve generalmente en la debilidad humana el origen de esta triste experiencia.

\section{Solidaridad en el pecado ${ }^{20}$.- Hemos señalado anteriormente el}

20 Sobre la solidaridad o relación entre el individuo y la comunidad, que ha recibido el nombre de "personalidad corporativa" (corporate personality), véase, H. W. RoBinson, "The Hebrew Conception of corporate personality": Beiheft zur Zeitschrift für die alttestamentliche Wissensohaft 66, Berlin 1936, 49-62; J. de Fraine, Adam et son lignage, Bruges 1959; J. ScHARBERT, Solidarität im Segen und Fluch im. Alten Testament und in seiner Umwelt, Bonn 1958; ID., Heilsmittler im Alten Testament und im Alten Orient, Freiburg 1964. 
carácter comunitario de la ética israelita, que le viene de su pasado nómada. Esta concepción comunitaria de la vida ha impregnado la noción de pecado. El lazo de sangre real o ficticio crea una solidaridad entre los miembros de la tribu ${ }^{21}$. La salud, el bienestar, la prosperidad, la bendición de Dios son un patrimonio común en el que participa el individuo, siempre que guarde las normas que regulan la vida común. De este modo la vida del clan está regida por la ley de solidaridad, tanto para el bien como para el mal.

Desde nuestro punto de vista es oportuno señalar el papel que juega el individuo culpable en el seno de la comunidad. Es una convicción profunda de los autores bíblicos que una calamidad puede alcanzar a todo el grupo por el pecado de un individuo. Como, por otra parte, no se distingue entre el pecado, la culpabilidad y el castigo, se da a veces el caso de que una comunidad se declara culpable por la falta de un individuo, o simplemente que la comunidad carga con el castigo de un crimen cometido por un individuo. Los ejemplos son numerosos en este sentido. Basta citar el caso de Akan, donde todo el pueblo "viola la alianza" por la falta de una persona y es causa de un castigo para todo el grupo (Jos 7, II). El caso de Abimelek es elocuente. El pecado de un solo individuo habría podido comunicarse a todos los ciudadanos (Gen 26 , Io). En estos casos parece que la culpa de un individuo pasa a un grupo. Otras veces y es lo más frecuente, se afirma simplemente que la culpa de un individuo desencadena el castigo de una comunidad. Así, el pecado de David haciendo el censo del pueblo ocasiona una peste mortal (II Sam 24, I-7). Achaz, por su falta de fe, es responsable del castigo que va a venir sobre Judá (Isa 7, r7).

La legislación israelítica manifiesta esta misma mentalidad. La acción culpable de un individuo ejerce una influencia nefasta sobre todos los miembros del grupo, y tal individuo debe ser extirpado de en medio del pueblo. De lo contrario, todo el grupo quedaría bajo la maldición o la desgracia que una acción mala desencadena (Gen 17, I4; Ex 12, 15; Lev 7,$20 ; 17,4.9 .14$, etc.).

No solamente hay solidaridad entre contemporáneos, sino también entre generaciones sucesivas. El clan no es una sucesión de seres vivos, sino que en cualquier tiempo se presenta como una unidad orgánica y concreta, en la que están integrados los antepasados y los futuros des-

21 R. de Vaux, Les Institutions de l'Ancien Testament, Paris 1958, I, 26. 
cendientes. La conocida frase, diversas veces repetida de Ex 34, 6s (Cfr Ex 20, 5s; Num I4, I7s; Deut 5, 9s; Jer 32, 18s): "Yahvé, Yahvé, Dios piadoso y misericordioso, tardo para la ira y grande en gracia y fidelidad... pero que nada deja impune, antes bien castiga la iniquidad de los padres en los hijos y en los hijos de los hijos, hasta la tencera y cuarta generación", manifiesta claramente la mentalidad de que existe un lazo de unión entre las generaciones sucesivas: Dios investiga rigurosamente la descendencia para ver si los hijos son tan malos como los padres, y en el caso de que los encuentre culpables, los castiga, aunque tenga que esperar muchas generaciones ${ }^{22}$.

Es opinión diversas veces repetida en la Biblia de que el destienro ha venido por la acumulación de los pecados de los antepasados y de los presentes. Lev 26, 39: "A causa de la iniquidad de sus padres perecerán como ellos" (Cfr. Jer 9, I3; I6, II). A este texto hace eco Isaías $(\mathrm{I} 4,20)$ : "Preparad a sus hijos para la matanza, a causa de la iniquidad de sus padres". Las acusaciones de los profetas contienen frecuentemente una retrospección histórica en la que presentan el pasado de Israel como una historia de pecado, cuyo resultado es el Israel de hoy, que obra peor que sus antepasados, y de ahí que el juicio sea inevitable (Jer 2, 2-8; 7, 25-26; II, Iо; I6, I0-13; $\mathrm{Ez} \mathrm{I6;20)}{ }^{23}$.

Cuán arraigada estaba esta mentalidad lo manifiesta la sentencia de Lam 5, 7: "Pecaron nuestros padres y ya no existen y nosotros cargamos con sus iniquidades". Voces se elevarán contra esta manera de pensar que el pueblo había recogido y transmitía en un proverbio: "los padres comieron agraces y los hijos tienen la dentera" (Jer 31, 29; Ez I8, 20), pero el principio de solidaridad seguirá manteniéndose hasta los mismos albores del cristianismo (Sab 3, II-I2; 4, 3; Eccil 4r, 7).

Si la solidaridad de la raza fue un principio fundamental de los israelitas, se nota, sini embargo, una tendencia hacia el individualismo, constatable en el Deuteronomio que implanta la sanción individual por parte del juez humano (Deut 24, го.16), aunque conserve el principio de la retribución colectiva por parte de Dios (Deut 5, 9; 7, 9; II, 5-6), en la crítica aniteriormente citada de los profetas Jeremías y Ezequiel y en la doctrina de los sabios, que insisten en la responsabilidad personal ${ }^{24}$.

\footnotetext{
22 Ha sido J. Scharbert quien ha probado que éste es el sentido de la frase, véase "Formgeschichte und Exegese von Ex. 34, 6s und seiner Parallelen": Biblica 38 (1957) 130-150.

23 J. de Fraine, o. c., 88-92; J. Scharbert, Solidarität..., 210s.

24 J. HЕMPEL, o. c., 32-93.
} 
El A. T., sin embargo, nunca llegó a elaborar una síntesis entre estas dos mentalidades opuestas, que coexistieron a lo largo de la historia de Israel, aunque a partir del destierro la responsabilidad personal gana cada vez más terreno. $\mathrm{El}$ mismo $\mathrm{A}$. T. manifiesta, pues, vacilaciones en cuanto al principio de solidaridad, que en gran parte debe juzgarse como un resto de concepciones atávicas, y por tanto vehículo de la palabra de Dios, y no contenido de la revelación misma. Si por otra parte, es una convicción del A. T. que hay continuidad entre las generaciones, es debido a que "el pecado se objetiviza en estructuras sociales, en sistema de valores, en ideologías, en tradiciones, en costumbres, en comportamientos colectivos, en mentalidad común para todos los individuos de una sociedad" ${ }^{25}$. Se puede, pues, decir que el pecado de los antepasados condiciona la conducta de los descendientes, pero concluir a una transmisión hereditaria es dar un paso en falso, puesto que en todo caso la solidaridad supone las culpas actuales de los contemporáneos. Mediante estos pecados ellos se solidarizan con el de sus antepasados.

\section{El pecado original originante U ORIGEN DEL PECADo.}

Cuando el A. T. habla del pecado, centra más su interés en calificar y describir la acción y determinar sus consecuencias que en especular sobre su origen. Y cuando esto último ocurre, ordinariamente recurrren a la debilidad natural del hombre, que crea un terreno favorable para el pecado, como hemos visto antes. Los profetas, particularmente Jeremías, acuden a la obstinación o endurecimiento del corazón, creado por la costumbre de pecar; esto mismo hacen los sabios: "La necedad está ligada al corazón del niño. La vara de la corrección la apartará de él" (Prov 22, 15). Sólo un autor no se ha contentado con esta explicación y ha buscado más profundamente la causa del mal: es el autor de Gen 2-3.

A) El Relato del J. (Gen 2-3).--Estos dos capítulos se atribuyen al J, que escribió en la época salomónica, ciertamente antes de la catástrofe del Reino del Norte (a. 72I ${ }^{26}$.

25 A. GELIN, o. c., 37-38.

26 O. EISSFELDT, Einleitung in das Alte Testament, Tübingen 1956, 2 ed., 238. No comprendemos los argumentos de M. GUERRA, "La narración del pecado 
Su ensayo es extremamente singular. Se constata, en efecto, que es un relato totalmente aislado en el A. T. ${ }^{27}$. Su singularidad no sólo se manifiesta en el hecho de que nadie fuera de él ha buscado una causa más profunda del mal, sino también en que de hecho ningún autor bíblico denota conocer Gen 2-3, si exceptuamos el Sirácida y la Sabiduría, dos libros compuestos muy tardíamente. De esto se sigue, como muy bien nota N. Lohfink, que el contenido de Gen 2-3 no constituyó para los israelitas, objeto de fe vivida, sino pura especulación teológica, que muy poca influencia ejerció en la fe de Israel ${ }^{28}$.

Ante la dificultad de interpretación que ofrece un texto aislado y solitario, la pregunta fundamentai que se hace el exégeta es la siguiente: ¿Cuál es la intención didáctica del autor? o lo que es lo mismo, ¿por qué compuso este relato? Para responder a estas preguntas, el único medio que tenemos es el texto y su forma literaria.

I. Carácter mitológico.-Que el autor de Gen 2-3 ha empleado en su relato muchos elementos mitológicos, es hoy francamente reconocido por un gran número de autores ${ }^{29}$. Si hasta hace poco tiempo había cienta desconfianza y cierta reserva a dar esta etiqueta a Gen $2-3^{30}$, era debido al concepto racionailista y depreciativo del mito, que evoca espontáneamente una composición imaginativa, falsa, propia de la edad prelógica

oginal, un mito etiológico y parenético": Burgense 8 (1967) 58 que afirma que el cap. 3 del Gen. fue redactado en torno al destierro de Babilonia. El silencio que se observa de estos capítulos puede admitir otras explicaciones. Nosotros preguntaríamos más bien si en tal época era posible que un autor escribiera Gen. 2-3; tenemos, en efecto, de este itiempo el Código Sacerdotal, y no ha retenido Gen. 2-3.

27 Todos los autores señalan esta característica en Gen 2-3. Cfr. H. RENCKENS, Así pensaba Israel. Creación, Paraíso y pecado original según Gen. 1-3, Madrid 1960, 192-193; N. LoHFiNK, "Die Erzählung von Sündenfall": Das Siegeslied am Schilfmeer, Frankurt-Main 1966, 81; H. HAAG, o. c., 58; K. CoNDON, a. c., 22.

28 N. Lohfink, o. c., 81; J. Scharbert (Prolegomena..., 18-19, 79, 92) intenta en cierto modo probar lo contrario, pero no lo consigue. Véase a este respecto la nota crítica de N. LoHFinK, Biblica 49 (1968) 566.

29 J. L. MC Kanzie, "Myth and the Old Testament": Catholic Biblical Quarterly 21 (1959) 265-282; H. CAZELles, "Mythe et l'Ancien Testament": DBS VI, 246s.; C. WEstermanN, Genesis (Biblischer Kommentar), NeukirchenVluyn 1966, 26 ss.; A. IBÁNez ARANA, "Los mitos de los orígenes en la Biblia": Lumien 16 (1967) 407; K. KoNDON, a. c., 25; M. GuERRA, a. c., 51-54; P. GRELOT, Refléxions sur le problème du péché originel, Paris 1968, 38-45; G. VELLA, "El Capitolo III della Genesi e il peccato originale": Rassegna di Teologia 10 (1969) 85-86; O. LoRETZ, Schöpfung und Mythos. Mensch und Welt nach den Anfangskapiteln der Genesis (Suttgarter Bibelstudien 32), Suttgart 1968, 120.

30 Véanse en Cazelles (DBS VI, 246) las citas de autores como GuNKGH, BeA, EissfetDT, quienes negaban la existencia de mitos en el A. T. 
de la humanidad. Sin embargo, los estudios de los modernos etnólogos han modificado profundamente el concepto del mito ${ }^{81}$.

El mito no es un producto de la fantasía, sino de una facultad de intuición, que aprehende las realidades invisibles o transcendentales, hechos o sucesos que están fuera de nuestro mundo empírico. El mito presenta estas realidades intuidas en una forma estructurada, concreta y pintoresca, donde el hombre y Dios juegan cada uno su papel y donde se transpone en categorías propias del hombre (espacio y tiempo) lo que no es más que intuición de nuestra experiencia. La mente que ha creado el mito no es la filosófica, sino el hombre con todos sus sentimientos, inspiración e inteligencia, $y$ así ha plasmado en un drama vivo la imagen del mundo y los hechos de su experiencia religiosa. El mito cuenta cómo una realidad comenzó a existir, realidad que todavía hoy continúa; e indicando cómo algo comenzó a existir, se concreta asimismo el sentido y finalidad de tal realidad. Lo ordinario del mito es que trate de explicar una condición que se repite siempre y que se atribuye a una historia contingente ${ }^{32}$. No se trata de sucesos históricos reales, que acaecieron una vez, sino de un mensaje, un logos, una verdad que vale para todos los tiempos. Así se ve por qué en cierto sentido era necesario que el autor bíblico empleara el género mítico; sólo este género le daba la posibilidad de exponer ciertas verdades de valor perenne en los albores del mundo, verdades que el mitógrafo no puede probar con documentos históricos.

Recientemente O. Eissfeldt ha propuesto llamar a Gen I-II, relatos acrónicos, pues se trata de verdades atemporales, anhistóricas, valederas para todos los tiempos ${ }^{33}$. Ciertamente sería un abuso manifiesto del término historico, aplicarlo a Gen 2-3 ${ }^{34}$.

La existencia de elementos mitológicos en el relato de J no puede negarse. En Ez 28, I-I9, el profeta emplea el mismo mito en una diatriba contra el príncipe de Tiro. Se encuentran aquí los mismos motivos: estado de feiicidad primitiva, demora del hombre en el jardín del Edén, el jardín de Dios, una caída de su estado primitivo debido a la ambición, caída que lleva consigo la expulsión del jardín de Dios, y naturalmente

31 Una visión panorámica revalorizadora del mito puede verse en J. L. MC KenzIE, a. c., o en J. HENNINGER, "Mythe": DBS VI, 225-246.

32 A. M. Dubarle, o. c., 47.

88 O. EISSFELDT, "Achronische, anachronische, synchronische Elemente in der Genesis": Jahrbericht ex Oriente Lux, XVII 1963-1964, 148-164, citado por R. de Vaux, Revue Biblique 74 (1967) 284.

84 R. de VAux, Revue Biblique 74 (1967) 294. 
la muerte. La comparación entre los dos relatos manifiesta que Gen 2-3 es más modesto, y en $\mathrm{Ez} 28$ se encuentra el mito en su forma más primitiva ${ }^{\mathbf{8 5}}$.

No tenemos un relato extrabíblico paralelo a Gen 2-3, ni tampoco se encontrará, debido a que el autor bíblico ha elaborado varios mitos pertenecientes a diversas estructuras; pero los elementos de Gen 2-3, como la creación del hombre del barro, el paraíso, el árbol de la vida, el papel de la serpiente, el ser como dioses, la expulsión del paraíso, los querubines, etc., son formas tomadas de la mitología, donde se encuentran con la misma problemática ${ }^{36}$.

Siendo, pues, cierto que el género literario adoptado por el J es el mitológico, la cuestión importante es percibir su mensaje. Dado que el mito proclama únicamente un suceso simbólico y fuera de su significado no existe realidad alguna ${ }^{37}$, nos es obligado admitir que Gen ${ }^{2-3}$ no nos da ninguna noticia histórica ni ningún conocimiento científico sobre el estado primitivo del primer hombre. Como, por otra parte, el mito hunde sus raíces en la experiencia religiosa y proclama una verdad vaiedera para todos los tiempos, debemos aceptar que Gen 2-3 intenta exponer la experiencia del pecado humano y sus consecuencias; en definitiva, un hecho de aplicación universal: el hombre que peca frecuentemente y se rebela contra Dios ${ }^{88}$.

En verdad tal punto doctrinal es de suma importancia, puesto que el mito de Gen 2-3 enseña así que el pecado es algo contingente en la historia humana, es decir, que el pecado proviene de la libertad humana. El mal no procede de la constitución misma de la naturaleza, ni de la voluntad arbitraria de un dios, sino de la decisión del hombre.

Este hecho de experiencia universal, el pecado, es aquí presentado desde el punto de vista israelítico. El Dios de Gen 2-3 es Yahvé, el Dios de los israelitas. El pecado del hombre es una falta contra este Dios, que el hombre comete, seducido por la serpiente. Ahora bien, no debe caber duda alguna de que la serpiente es aquí el símbolo de los cultos de la

35 Sobre este oráculo véase W. ZimmerLI, Ezechiel (Biblischer Kommentar), Neukirchen-Vluyn 1956, 662.

36 Una breve comparación entre los mitos orientales y la Biblia véase en A. IbÁÑez ARANA, a. c., 398-405; H. CAZELles, a. c., 252-261. La comparación entre Gen. 2-3 y el poema de Gilgamesh, en J. ERrandonea, Edén y Paraíso. Fondo cultural mesopotámico en el relato bíblico de la Creación, Madrid 1966.

37 H. Schlier (Hochland, XLVIII, 1955-1956, 206) citado por J. HenNINGER, a. c., 245 .

38 N. Lohfinik, a. a., 94; P. Grelot, o. o., 54. 
fertilidad ${ }^{39}$. Estos constituyeron la gran tentación que amenazó con ahogar la fe Yahvista, como sabemos por Oseas, Jeremías, Ezequiel y la literatura deuteronomista. Así, pues, el gran pecado de Israel en su historia sirve para describir el pecado de la humanidad ${ }^{40}$. De este modo el autor tiene una finalidad parenética y pastoral: describiendo el pecado de la humanidad con los colores de los cultos de la fertilidad propina un buen antídoto al mal que padece Israel.

La conclusión que se impone es la siguiente: Gen 2-3 no da noticias históricas ni sobre el estado primitivo ni sobre el primer pecado, sino que se trata simplemente de una interpretación teológica, construída merced a la fe de Israel, de la experiencia que tiene el hombre del pecado, del que se dice que proviene de la libertad humana, y lleva consigo la separación de Dios.

Hay atro punto que debe tenerse en cuenta. Quien emplea el género mítico tiene una finalidad etiológica e intenta explicar por qué las cosas son así y no de otra manera. Que esta finalidad está presente en Gen 2-3 no cabe duda alguna, toda yez que su atención se centra en el dolor, la muerte, el trabajo costoso, de cuyas realidades intenta dar el motivo. Esta intención etiológica es también frecuente en otros mitos extrabíblicos. Conforme a la mentalidad mítica, que atribuye a una historia contingente las realidades y experiencias humanas, el $J$ atribuye también al pecado determinadas consecuencias, como el dolor, el trabajo, la privación de la amistad con Dios, etc. Este punto nos lleva a tratar de otra característica de Gen 2-3.

2. Reflexión sapiencial.-LLos estudios de estos últimos diez años ${ }^{41}$ han revelado que el $\mathrm{J}$ ha permeado su relato de temas sapienciales. El problema del bien y del mal, del bienestar y la desgracia, la vida y la muerte, la condición humana, la astucia, la tentación, la conciencia culpable son todos motivos que cautivan la atención de los sabios. Este ambiente sapiencial permite afirmar que nos encontramos aquí con un ensayo de teología reflexiva, en el que la fe de Israel trata de dar solu-

\footnotetext{
89 F. HVIDBERg, "The Canaanitic Background of Gen I-III": Vetus Testamentum 10 (1960) 285-294.

40 O. LORETZ, o. c., 121-122.

11 A.-M. DubarLe, Les Sages d'Israel, Paris 1947; ID., Le péché originel dans l'Ecriture, Paris 1967, 39-74; H. RENCKENS, o. c., 175 196; L. Alonso Schokkel, "Motivos sapienciales y de Alianza en Gen. 2-3": Biblica 43 (1962) 295-315; N. LOHFINK, "Genesis 2f. als "geschichtliche Aetiologie": Scholastik 38 (1963) 321-334.
} 
ciones a los problemas prácticos que presenta la vida, sobre todo, la experiencia del dolor.

Además, el autor se ha servido del esquema clásico de la Alianza para exponer en un relato sus reflexiones y las soluciones que su fe le daba ${ }^{42}$. Hay un esquema de la Alianza que se articula en varios tiempos: Iniciativa divina, es decir, Dios concede favores; Dios impone las cláusulas de la Alianza; el hombre las quebranta; Dios le castiga y le reconcilia consigo. A poco que se observe, se nota inmediatamente, que el J ha seguido en su relato el esquema clásico de la Historia de da Salvación.

$\mathrm{El}$ autor del relato, pues, se sirve de la teología israelítica, de su fe para interpretar la condición humana. Su fe le indicaba que la desgracia, los males que el pueblo padecía, ia separación de Dios tenían su origen en el quebrantamiento de las cláusulas de la Alianza y no en Dios que favorecía continuamente al pueblo. Guiado por esta fe, que nosotros no podemos en todos sus puntos aceptar, el J da la misma explicación del mal y del estado de maldición en el que se halla sumida la humanidad: todo ello es debido al pecado. De nuevo observamos aquí, que el J describiendo el pecado del primer hombre, en realidad, describe la experiencia de todo pecado.

Pero, ¿por qué habla de un primer pecado, cometido por una pareja singular?

3. Mentalidad de clan del $J^{43}$.-Israel conservó de su pasado una mentalidad que pudiéramos llamar propia de clan, según la cual el individuo estaba absorbido por la comunidad, a través de la cual recibe su bienestar como su desgracia. En grupos nómadas o procedentes del nomadismo, es fuerte esta conciencia de solidaridad entre los miembros, ya que es inconcebible que un individuo pueda vivir sin estar integrado en un grupo. El clan está dirigido por un jefe y se consideran todos parientes, descendientes de un padre común. Cuando un grupo entra en relaciones con otro y se llegan a integrar los dos, esto se expresa de una manera genealógica, haciendo derivar a los dos grupos de un mismo progenitor. Las listas genealógicas manifiestan así las relaciones sociolb́gicas y geográficas tanto como las biológicas. Debido a la profunda solidaridad que domina a todos los miembros, sean pasados, presentes

42 Sobre este tema véase, L. Alonso-Scoekel, a. c., 305-309.

43. Una buena $y$ breve exposición de esta mentalidad en J. Scharberr, Prolegomena... 31-44. 
o futuros, apenas se diferencia entre el antepasado común y la tribu actual.

De aquí brota otra característica propia de la mentalidad de clan. Las experiencias, costumbres, ritos, defectos, etc., se explican recurriendo al antepasado, al cuai se le atribuye una acción que explica el uso actual. Esto es lo que se llama mentalidad etiológica. Por fin, a veces, se le atribuyen al antepasado cualidades, acciones, etc., que sirven para diseñar la imagen típica de la tribu, de la que el personaje es progenitor.

Que el J está imbuído de esta mentalidad genealógica, etiológica y tipológica, propia del clan, es cosa clarísima.

En el capítulo io del Gen hace derivar a todos los pueblos conocidos de un antepasado común que lleva su nombre. Así, los egipcios descienden de un hombre que se llamaba Egipto; los arameos, de un tal Aram; los cananeos, de un tal Canaan. Nada, pues, tiene de extraño que conciba a toda la humanidad, como un gran clan, cuyo antepasado Adán (= hombre) lleva el nombre del grupo.

Igualmente, el J atribuye a una acción del antepasado una situación actual. Los Cainitas o Kenitas viven errantes en el desierto, a causa de un crimen cometido por su antepasado (Gen 4). Las tribus de Simeón y Leví han desaparecido en castigo de una falta de su antepasado (Gen 34; 35, 22). Los israelitas no comen el tendón de la articulación del muslo, debido a una experiencia vivida por el antepasado Jacob (Gen 32, 26-33). Nada, pues tiene de particular que el autor atribuya a una mala acción del antepasado común a toda la humanidad las experiencias dolorosas de la existencia del hombre.

Finalmente Adán puede ser simplemente tipo de todos los hombres, como Cam- Canaan es tipo de los libertinos cananeos (Gen 9, 20-25).

4. Valoración del relato del J.-Por varios caminos hemos llegado a concluir que Gen 2-3 describe la experiencia de todos los hombres, o lo que es lo mismo, caracterizando a Adán, en realidad, el autor describe la experiencia común del hombre que peca: Adán es tipo de la humanidad. Esto lo exige el lenguaje mitológico, la reflexión sapiencial que medita sobre la conducta humana y la mentalidad de clan propia del hombre que piensa solidariamente.

Un segundo punto es importante : no es sólo ia experiencia de todo pecado lo que él describe, sino que también quiere decir que el pecado 
es algo contingente, es decir, el mal en el mundo no se debe a que haya dos principios uno bueno y otro malo, o que el hombre esté constitutivamente mal hecho, sino que brota de la libertad humana, como un efecto de la rebelión humana contra Dios. A esta adquisición el autor ha llegado a través de la experiencia reiigiosa vivida por Israel, como señalábamos antes. La diferencia precisamente entre Gen 2-3 y los relatos extrabíblicos de los orígenes se nota en este punto: mientras en estos últimos, el mal se explica por un accidente o por un fato a nivel cosmogónico, para el J el mal brota de un acto libre del hombre ${ }^{44}$. Es aquí donde hay que ver la interpretación israelítica dada al mito.

Apenas se puede sacar más de Gen 2-3 a favor de la doctrina del pecado original. La mentalidad de clan, que es la base del relato, no podemos secundarla completamente. Es evidente el artificio. Nada nos obliga a admitir que los egipcios desciendan de un tal Egipto, y por tanto tampoco nadie nos obliga a creer que todos los hombires provienen de Adán (= ei hombre). Como por otra parte, el mito hace derivar de una historia contingente las experiencias de la vida, en vez de aceptarlas como condiciones de la naturaleza humana, es muy posible que el autor pensara que el dolor del parto, el trabajo, etc., sean efecto del pecado primero de la humanidad, pero nada nos obliga a admitirlo, pues el mito no da conocimieritos naturales.

Un tercer punto conviene señalar. El J en su historia primitiva dibuja a grandes rasgos la progresión del mal en la humanidad. Después del primer pecado sigue una larga serie, el fratricidio de Caín, la poligamia y venganza de Lamek, hasta llegar a la constatación de Gen 6, 5: "Vio Yahvé que la maldad del hombre sobre la tierra era grande, y que todo el objeto de sus pensamientos de su corazón eran siempre el mal". Después deì diluvio, el pecado sigue su marcha triunfante, como lo demuestra el episodio de Cam-Canaan (Gen 9, I8-28), la torre de Babel (II, I-9). Mediante estos relatos típicos y paradigmáticos, el J ha conseguido exponer el progreso del mal en la humanidad y el abandono en que yace por parte de Dios, del que no podrá salir, si no es por la generosa intervención de Yalıvé, que elige a Abrahán (Gen I2, I-3). Aquí comienza la etapa de la bendición y de la vida, a la que todos pueden participar, en tanto se hagan solidarios del clan de Abrahán. Al lado, pues, de la mal-

44 P. Grelot, Réflexions... 38-45; N. LohFinH, "Die Erzählung von Sündenfall": Das Siegeslied am Schilfmeer, Frankfurt-Main 1966, 83-89. 
dición y del mal, que arrancan del pecado, hay una bendición que comienza con Abrahán y se extenderá a todos los pueblos.

B) El Pecado original de Israed ${ }^{45}$.-Sin podernos explicar el motivo ${ }^{46}$, el relato del $\mathrm{J}$ no encontró continuadores; ni siquiera parece haber sido conocido por los autores posteriores, sino es muy tardíamente.

Sin embargo, la reflexión sobre el origen del pecado toma otra dirección. Los profetas e historiadores de Israel buscarán el origen del pecado de Israel, no del hombre en cuanto tal, como lo había hecho el J.

Estos autores se encuentran con un pueblo pecador, infiel a la Alianza y dominado por el sincretismo religioso. Llevados por su celo divino, vituperaban crudamente los defectos de sus contemporáneos y profundizando en el mal, retiroceden a los antepasados, en quienes ya encuentran los síntomas de degradación y de infidelidad a los favores divinos.

Así, Oseas retrocede hasta Jacob, padre del pueblo, que ya fue un ladrón e impostor (Os 12, 4.13), a la apostasía de Baal-Peor, pecado cometido en vísperas de la entrada en Palestina (Os 9, ro que alude a Num 25, I-4), al crimen de Guibea (Os 5, 9 y ro, 9 que aluden a Jue 19). Eil recuerdo de estas culpas antiguas se une a la enumeración de los pecados presentes (Os 4; 6, 7-10) que hoy soportan y que deben expiar.

También a Jacob recurre el II Isaías, durantẽ el destierro: “Tu primer padre pecó y tus representantes me han sido infieles... Por esto entregué a Jacob al anatema y a Israel a los oprobios" (Isa 43, 27).

Igualmente Jeremías encuentra el pecado en los orígenes de Israel. Después de la salida de Egipto, pasó un tiempo en que Israel fue fiel a su Dios: era el tiempo de la juventud; pero "ya desde antiguo quebrantaste tu yugo y rompiste tus ligaduras y dijiste: no serviré más" (Jer 2, 20). Ya los antepasados se alejaron de Dios antes de entrar en la tierra prometida. A este don de Dios de la posesión de la tierra, respondieron los antepasados con la idolatría (Jer 2, 5-8), a cuyo pecado han vuelto los contemporáneos del profeta (Jer II, Io). Incluso estos son peores que sus padres.

\footnotetext{
45 Sobre lo tratado en este párrafo, véase A.-M. DuBarLe, La péché órtyi nel... 25-34, y sobre todo J. Scharbert, Prolegomena... 78-93.

46 No es fácil comprender por qué estos capítulos 2-3 del Génesis no fueron citados por los autores posteriores. Quizá el motivo sea el apuntado por R. RENDTORFF, "Genesis 8, 21 und die Urgeschichte des Jahwisten": Kerygma und Dogma 7 (1961) 76: Gen. 2-3 recoge tradiciones extrabíblicas y en un momento en que los círculos proféticos empeñaron una guerra sin cuartel contra el sincretismo, no parecía muy ortodoxo recurrir a estas tradiciones un tanto equívocas.
} 
Muy gráfico es Ezequiel: "Mira, todo proverbista hará un proverbio tocante a ti, diciendo: cual la madre, tal la hija. Eres digna hija de tu madre... vuestra madre era una hitita y vuestro padre un amorreo" (Ez 16, 44-45). El origen sincretista del pueblo explica la tendencia sincretista que siente Israel a la idolatría.

Conviene notar que este recurso a culpas antiguas no se hace con la intención de excusar a sus contemporáneos, sino que lo que intentan los profetas es poner en claro que tal continuidad en el pecado no puede quedar impune.

El E, compuesto hacia el siglo viII y procedente del Reino dei Norte, encuentra el pecado original de Israel en la apostasía cometida inmediatamente después de la alianza en el Sinaí con el becerro de oro. Esta apostasía es el pecado prototipo de Israel que explica la instauración de los becerros en Betel y Dan (Ex 32 y I Re 12, 25s). También el Deuteronomio recuerda la apostasía del Sinaí, como el pecado primitivo de Israel (Deut 9, 7-21), al cual siguieron otros pecados (Deut 9, 22-23).

Finalmente, el Deuteronomista, escribiendo durante el destierro, se pregunta cómo ha podido llegarse a esta situación y la respuesta la encuentra en la historia. Desde un punto de vista religioso interpreta el material disponible y encuentra un sinfín de infidelidades en todas las épocas. La primera la encuentra ya en Qades en el intento fallido de ataque a Canaán por el Sur (Deut I). Después sigue un período en que Israel se mostró fiel a su Dios (Deut 2-4). Pero una vez tomada la Palestina, las infidelidades se suceden continuamente. El esquema adoptado en el libro de los Jueces nos presenta frecuentes apostasías a las repetidas intervenciones salvíficas de Yahvé. La erección de los becerros de oro por Jeroboam (I Re I4, 8ss) es como un pecado original, que es continuado y ratificado por todos los reyes de Israel. También Judá perpetró semejante apostasía bajo Manasés (I Re I7, I9s). Del peso de tanta iniquidad es consciente el rey Josías: "Grande y ardiente debe ser la cólera de Yahvé contra nosotros, porque no escucharon nuestros padres las palabras de este libro a fin de cumplir todo lo que está escrito para nosotros" (II Re 22, 13). Sin embargo, ya es tarde: "Así habla Yahvé: $\mathrm{He}$ aquí que voy a hacer el mal sobre este lugar y sobre todos sus moradores... porque me han abandonado y han quemado perfumes a dioses extranjeros" (II Re 22, I6-I7).

En resumen, todos buscan en el pasado el pecado prototipo y pri- 
mitivo de Israel, que explique el mal desencadenado y sus consecuencias. Cada autor lo ha descrito de diferentes maneras, pero todos ellos creen que al favor divino ya en el pasado el pueblo respondió con la infidelidad y la apostasía. Ya encontramos aquí un primer contacto con el J. Todos ellos afirman que primero fue la relación amical con Dios, el bienestar, el tiempo de la juventud. Es el hombre o Israel que se separa de Dios, complicando así sus relaciones con El.

¿Qué valor tienen estas afirmaciones? En primer lugar, este pecado del pasado, que el J busca en la edad primitiva de la humanidad y los profetas y escritores en el período primitivo de Israel tiene el carácter de prototipo. Claro está este aspecto en el Deuteronomista, que en Deut I describe el primer pecado y en Deut 2-4, un período en que Israel fuie fiel a Dios. Ambos momentos son modelos o tipos que el autor presenta a sus contemporáneos como ejemplos típicos.

En los textos citados, además, es clara la suposición de que las culpas pasadas condicionan en cierto modo la conducta de sus contemporáneos. Son en definitiva conscientes de la experiencia: cual madre, tal la hija, como dice Ezequiel; y es que el pecado crea una atmósfera, unas estructuras o instituciones (recuérdese los becerros de Betel y Dan) que inducen al pecado, o condicionan, o sitúan al hombre en un ambiente propicio al pecado. No se debe olvidar que en los textos citados, los profetas recuerdan también los pecados actuales de sus contemporáneos, mediante los cuales ellos continúan la mala conducta de sus antepasados. Este punto no conviene olvidarlo en una elaboración de la doctrina del pecado original.

C) Doctrina de P en torno a la IRRUPCión del PeCAdo EN El MUNDo.-Durante el destierro, en una situación delicada, la escuela sacerdotal, para saivaguardar las tradiciones religiosas de Israel, compone un ensayo de historia general, donde integra las instituciones religiosas y culturales. El esquema de su historia tiende hacia Israel, depositario del verdadero culto. Por eso, en cada escalón reduce cada vez más su mirada. Este autor conoce a sus predecesores: el J, el E y el D; usa sus tradiciones y dispone de otras nuevas. Con frecuencia las interpreta y se separa de ellas, no por arbitrariedad, sino con el fin de adaptar las antiguas tradiciones al desarrollo que la revelación ha alcanzado en su tiempo.

Limitándonos concretamente a nuestro tema, $\mathrm{P}$ manifiesta una con- 
cepción muy distinta de la del J. Si para este úitimo, la historia primitiva era un período de maldad y desgracia para la humanidad, que concluye con la catástrofe del diluvio y la amarga constatación de Gen 8, $2{ }^{47}$, para $\mathrm{P}$, en cambio, la historia primitiva parece ser un período ideal. La narración de la creación culmina con la aprobación solemne de que todo estaba muy bien (Gen I, 3r). De Adán, y a través de Set -único hijo mencionado- parte una genealogía compuesta de hombres piadosos que termina con Noé (Gen 5). P no conoce una genealogía pecadora y maia, y ningún síntoma permite suponer que el mal exista ${ }^{48}$. $\mathrm{El}$ autor, dispone luego de la narración del diluvio, catástrofe que fue causada por el mal que dilagaba en la humanidad. De ahí que anteponga la observación siguiente, que no debe limitarse sólo al hombre: "la tierra entera se había corrompido en la presencia de Dios y estaba llena de violencias. El fin de toda carne viene ante mí, porque la tierra está llena de violencias por culpa de ellos" (Gen 6, II-13). Esta constatación está abiertamente en oposición con la sentencia de Gen I, 3r. La maldad existente amenaza con provocar la vuelta al caos primitivo; y de hecho, según esta tradición, el diluvio es dibujado como un retorno al caos (Gen 6, I7; 7, ir).

El autor sacerdotal no se pregunta sobre el origen del mal, sino que se contenta con constatar su existencia. Pero, ¿de qué mai se trata? L. van den Winigaert ${ }^{49}$, apoyándose en la tesis de Koch ${ }^{50}$ ha probado con suficiente seguridad que $P$ tiene diversas concepciones del pecado, conforme al diverso estadio de la revelación en el que el mal ocurre. Sólo después del Sinaí, emplea los términos comunes para designar el pecado como $h t$ ' y ' $w n$. Antes del capítulo 25 del Exodo, sólo empieza hms (Gen 6, II.13), término eminentemente profético (ocurre 26 veces en los profetas), y que significa la violación de los derechos de los de-

47 Cfr. R. RENDTORFF, $a, 0 ., 75$.

48 Con frecuencia se ha indicado oue el decrecimiento de la edad de los Patriarcas de la lista genealógica de $P$ (Gen. 5) era el medio de aue se valía este autor para expnner el progreso del mal. cfr. G. von RAD, Die priesterschrift im Hexateuch, Stuttgart 1934, 171; A.-M. DuBARLE, Le péché originel dans l'Ecriture. Paris 1967, 72.

Sin embargo, H. HAAG (o. c., 44, nota 34) ha probado aue tal indicio en reallidad no existe. Por su parte $L$. van den WIJNGAFRT, "Die Sünde in der prifsterschriftlichen Urgeschichte": Theolonie und Philosonhie 43, 1968, 36-37, comiparando las listas sacerdotales con las listas sumerias de los héroes prediluvianos, ha ratificado la opinión de $\mathrm{H}$. HAAG.

49 L. van den WiJnsaerT, a. c., 49-50.

50.K. KoCH, "Die Eigenart der priesterlichen Sinaigesetzgebung": Zeitschrift für Theologie und Kirche 55 (1958) 455s. 
más. Emplea, además, el término sht, que tiene el significado general de corromperse y no es una designación específica del pecado, que sólo será posible, cuando exista el verdadero culto a partir del Sinaí ${ }^{61}$.

Comparando la historia primitiva del J y la de $\mathrm{P}$, se observa una gran reserva por parte del Código Sacerdotal. Este último se contenta con decir que el mal, la injusticia existe, y de la cual es responsable el hombre $(\mathrm{Gen} 6, \mathrm{I} 3)$. En esto coincide con el J. Este último autor tiene además el relato del primer pecado, y conoce una descendencia de pecadores, la de Caín, en la que el mal crece y progresa. Conociendo la mentalidad del J, ninguno de estos dos puntos debe ser exagerado, ni tenido en gran importancia. Al $\mathrm{J}$ le gusta atribuir cada una de las instituciones a un primer hombre. Si Caín es el primer labrador $(\operatorname{Gen} 4,2)$ y luego el primer edificador de ciudades (Gen 4, I7), Yabal, el primer pastor (Gen 4, 20), Yubal, el primer músico (Gen 4, 2I), no tiene nada de particular que diga también quién es el primer pecador ${ }^{52}$. Tampoco tiene nada de extraño que describa una descendencia pecadora, dada su mentalidad de clan.

$\mathrm{P}$, en cambio, no conoce o no quiere conocer el relato de Gen 2-3. Este silencio es más chocante, si se considera que $\mathrm{P}$ ha conocido a Ez $28^{\text {t58 }}$, donde yace un mito paralelo a Gen 2-3 sobre la caída del primer hombre. $\mathrm{P}$, por tanto se separa voluntariamente de la representación mítica del J y de Ez 28. Parece, pues, que el relato del J no tenía para él mayor importancia.

Además se separa del J, sustituyendo la descendencia mala de Caín por una genealogía de hombres piadosos, en los que no se advierte para nada los síntomas del pecado.

No cabe duda, pues, de que $\mathrm{P}$ pensaba de muy distinta manera de como lo hacía el J. Para él es un hecho, y esto le basta, que el mal, la violencia (no todavía el pecado propiamente dicho) existía; preguntarse sobre el origen del mal, no le pareció conveniente, y el relato del J se le antojaba como sobrepasado.

D) Los Libros SAPIENciales. - Dado que los sabios intentaban la formación integral del individuo, por su mente pasan las diversas expe-

51 L. van den WIJNGAERT, a. o., 50.

52 H. HAAG, o. c., 56 . $45-47$.

68 Este punto lo ha probado suficientemente L. van den WIJNGAERT, $a . c$, 
riencias de la vida humana, y naturalmente también el pecado y la desgracia.

Es el Ecclesiástico, el primer libro, cuyo autor manifiesta conocer el relato del primer pecado ${ }^{54}$. En un contexto, no exento de misoginia, dice: "Por la mujer comenzó el pecado, y por causa de ella todos perecemos" (Eccli 25, 24).

Se ha de notar que el término mujer está sin artículo, y el autor puede referirse al género femenino, a la mujer en general. Quizá así interpretaba él a Eva ${ }^{55}$. Por lo demás, ni siquiera es cierto que el autor se refiera a Genı 2-3. Puede aludir también a Gen 6, I-4, texto que fue ampliamente comentado por la literatura apócrifa posterior ${ }^{56}$. Dado el caso que se refiera al relato del primer pecado, se ha de notar que la única consecuencia que saca es la muerte, y para nada habla de una falta hereditaria. Que a este texto no se le debe dar gran importancia, es la opinión común de los exégetas ${ }^{57}$. Se trata, en realidad, de un texto aislado. En todo los demás lugares, el Sirácida considera la muerte como el destino natural del hombre, y expresa este pensamiento con términos que manifiestamente se inspiran del J (Gen 2, 7): "De la tierra formó el Señor al hombre, y de nuevo le hace volver a ella" (I7, I. Cfr. I7, 25; 40, II, etc.). Dado que esta idea la repite constantemente, lo más fácil es considerar Eccli 25, 24, como una salida de tono, provocada por el contexto misógino, en que está incluída. Los males y la muerte parecen ser para él normales y propios de la experiencia humana $(\mathrm{I} 7,3 \mathrm{I})$.

Tampoco del libro de la Sab, otro escrito que conoce a Gen 2-3, se puede sacar nada de provecho para la doctrina del pecado original. El pasaje más importante a este respecto es el siguiente: "Por la envidia del diablo entró la muerte en el mundo y la experimentan los que ie pertenecen" $(2,24)$. Generalmente se cree que el autor se refiere a la serpiente del Paraíso, que es identificada con el diablo. Que la envidia del diablo sea la causa de la entrada de la muerte en el mundo, es lo que asimismo dicen otros apócrifos judíos, para quienes, al ser expulsados de los cielos el diablo y los ángeles, por no querer adorar a Adán,

54 Un poco antes, el libro de Tobías $(8,6)$ cita a Gen. 2, 18.

55 B. J. MALINA. "Some Observations on the Origin of Sin in Judaism and St. Paul": Catholic Biblical Quarterly 21 (1969) 24.

56 B. J. MaLina, $a$. c., 18-34.

57 V. HAMP, "Paradies und Tod": Festschrift für J. Schmid, Regensburg 1963, 107; A.-M. DubarLe, Le péché originel... 79-86. 
imagen de Dios, llenos de envidia, sedujeron a nuestros primeros padres ${ }^{68}$.

El autor manifiestamente no entiende por muerte el simple deceso corporal, sino más bien la existencia desgraciada de los impíos y la segunda muerte. Estos, los impíos, son los que verdaderamente mueren (I, I6). Su perdición es el resultado de sus extravíos y de sus pecados $(\mathrm{I}, \mathrm{I2})$. Para los justos, en cambio, la muerte no es más que una apariencia $(3,2)$. En realidad no mueren, ya que su esperanza está llena de inmortalidad $(3,4)$, y Dios, después de diversas pruebas los ha hallado dignos de Sí $(3,5)$. En efecto, Dios creó el hombre para la incorruptibilidad $(2,23)$, que es un objetivo que todos pueden alcanzar y que depende de cada uno.

Así, pues, el autor no considera el deceso corporal como una pena del pecado. Ni tampoco deduce de la falta del primer hombre (dado que se refiera a ella), la universalidad de la muerte, ya que, según él, la muerte la experimentan sólo los impíos. La incorruptibilidad, la eternidad, la vida es un don de Dios dado al hombre $(2,23)$, que los fieles buscan con empeño. Sin embargo, tentados por el envidioso diablo, pueden incurrir en la muerte, es decir, perder la vida y la incorruptibilidad.

Esta es, en resumen, la doctrina del autor, en la que no se sorprende la más mínima alusión a una falta hereditaria, es decir, al pecado original.

\section{CONCLUSION}

El problema del pecado ha preocupado hondamente a los autores bíblicos que han recurrido a una extrema variedad de términos para calificar esta experiencia humana. Y no sin motivo, ya que en él han visto la oposición al plan divino con las consecuencias que llevaba consigo: maldición, desgracia, separación de Dios, etc.

Son asimismo conscientes de su extensión universal. Todos los hombres se encuentran afectados por él. La condición humana, abandonada a sí misma es una condición pecadora, privada de salvación. De este estado sólo el auxilio de Dios puede saivarla.

58 Véanse las citas de la Vida de Adán y Eva y del Apocalipsis de Moisés en B. J. MaLina, a. c., 24-25. 
Dada esta conciencia tan aguda del pecado y del mal que atañe al hombre, no es extraño que buscaran la causa de tal situación. Sin embargo, acerca de este punto no hay una doctrina formal y dogmática, impuesta por la Escritura. Los autores han opinado diversamente, aunque no se puede hablar de contradicciones, al menos en puntos esenciales.

Los profetas e historiadores se han preocupado de buscar el origen del pecado dentro de Israel. Todos ellos encuentran en el pasado un pecado prototipo, que ahora todos soportan, y al que en el correr de los tiempos se han sumado otros, incluso los de los contemporáneos, de tal manera que hacen inevitable el juicio de Dios. Tal continuidad o solidaridad en el pecado se explica por el hecho de experiencia ordinaria de que el pecado crea un ambiente, una atmósfera de la que el individuo no puede liberarse.

El J, persuadido de la universalidad del pecado, intenta dar una explicación del mal en que se halla sumida la humanidad. Su trabajo es un ensayo de solución que se apoya en varios presupuestos:

-En primer lugar, conforme a la mentalidad general semítica, todos los aspectos dolorosos de la existencia humana son considerados consecuencias del pecado.

$\rightarrow$ Ahora bien, las desgracias, la separación de Dios, incluso esta fragilidad que el hombre experimenta en sí mismo, son comunes a todos los hombres. Esto no se explica si no es recurriendo a un pecado cometido en los albores de la humanidad.

- Imbuído de una mentalidad característica del clan le resuitaba relativamente fácil concebir a toda la humanidad como un gran clan, en el que el comportamiento del progenitor tuvo consecuencias desastrosas. tarlos.

Es evidente, que varios de estos presupuestos no podemos hoy acep-

En concreto, la idea de una primera pareja en el origen de toda la humanidad no puede considerarse como contenido de la revelación. El artificio de que se ha valido es manifiesto. Por otra parte es generalmente aceptado que $\mathrm{P}$ habla de la creación de la humanidad en general $(\text { Gen } 1,26)^{69}$.

En segundo lugar, considerar las experiencias dolorosas de la vida del hombre y de los animales, como consecuencias del pecado es una

69 H. HAAG, Biblische Schöpfungslehre... 43. 
idea tan impregnada de mentalidad semítica, que hace dudar si esto no es más que vehículo de la revelación, y no contenido de la misma. La doctrina de los sabios que consideraban, el dolor, la muerte, etc., como el destino normal del hombre, nos invita a ser reservados en este punto ${ }^{60}$.

Por último, tampoco, puede probarse por el A. T., una transmisión del pecado por generación. La salud, el bienestar viene al individuo a través del grupo; y para pertenecer a la comunidad no es necesario la pertenencia física y biológica al grupo, sino declararse solidarios con el clan. Si esto es así, no se ve por qué se ha de pedir la generación física para contraer la maldición y el pecado.

En definitiva, la doctrina católica del pecado original no puede basarse en el A. T. en todos sus puntos. Y se tiene la impresión de que el mismo autor J estaría extrañado de la serie de interrogantes que nos presentamos acerca de su texto.

60 A.-M. DUBARLE, Le péche originel... 188.

C. Mielgo, O. S. A. 